\title{
The Immediate Effects of Kinesio Taping on the Maximal Power and Muscle Activity of Erector Spinae in Normal Subjects
}

\author{
Moon-Hwan Lee \\ 22 Century Spinal Institute, C\&D Health, Jinju city, Korea. \\ Seong-Yeol Kim \\ Department of physical therapy, Kyungnam University, Changwon city, Korea
}

\begin{abstract}
The purpose of this study was to evaluate the effects of Kinesio taping(KT) on the maximal power and muscle activity of erector spinae. 30 male subjects were allocated in this study and randomly divided into experimental and control groups. All subjects were measured for maximal power of trunk extensors and muscle activities of iliocostalis lumborum, longissimus, and multifidus between pre and post experiment. Maximal power was calculated using a dynamometer(Power Track II, JTECH medical, USA), and muscle activities were calculated using a surface EMG(MP150 BIOPAC System Inc. CA. USA). Maximal power of trunk extensor showed no significant difference between pre and post intervention in both groups( $p>0.05)$. Muscle activity of iliocostalis lumborum, longissimus, and multifidus showed no significant difference between pre and post intervention(p>0.05). Finally, there was no significant difference between Experimental and control group in maximal power and muscle activity of trunk extensor. These study results suggested that $K T$ did not affect increase or decrease in maximal power and muscle activities of trunk extensor.
\end{abstract}

Keywords: Kinesio taping, Muscle activity, EMG.

\section{I . INTRODUCTION}

Kinesio tape(KT) is an elastic therapeutic tape, which was invented by Kenso Kase in the 1970s. KT has a thickness of about human skin, and can be stretched up to $20-40 \%$ of its original length longitudinally [1]. The acrylic mounting of this new type of KT differs from traditional white athletic tape in that it is designed with a wave-like grain. As the specialized grain and elasticity of the tape is applied to the skin, it provides a pulling force to the skin and creates more space by lifting the fascia and soft tissue under the areas where it is applied [2]. KT, which is an organized wrapping technique over and around the muscles to assist and give support, is believed to reduce pain, swelling and muscle spasms, increase muscle strength as well as improve the gait pattern and enhance the functional outcome of patients with osteoarthritis and patellofemoral pain syndrome [3]-[7].

The theory behind such effects of KT is that when nonstretched tape is applied to muscle which is extended to its maximum, skin would be lifted upwards due to taping once muscle returns to its original position, which would increase the space between skin and muscle and subsequently allow

\footnotetext{
*Corresponding author,Email: okpt75@kyungnam.ac.kr Manuscript received Jul. 25, 2012; revised Sep 25, 2012; accepted Oct 05, 2012
}

blood, lymph fluids and tissue fluids to have increased circulation in this enlarged space [2]. However, this hypothesis is limited to pathological situations as shown from previous studies.

Otherwise, some previous studies which KT applied to the normal subjects were reported contradictory results. For examples, Dr. Kenzo Kase claimed that one of the effects of the $\mathrm{KT}$ is the increase in muscle strength [2]. Slupik et al [8] determined the effect of KT on bioelectrical activity of vastus medialis muscle. The results revealed an increase in the electromyographic activity of the vastus medialis muscle after 24 hours of KT, and even maintenance of motor activity after 2 days of KT and after removal of the tape. However, Morrissey [9] stated that because muscle length shortens when tape is applied to dynamically relaxed muscle, length-tension curve in resting state would shift to the left and muscle activity would increase as appropriate cross-bridge of actin and myosin takes place. Conversely, Alexander et al [10] stated that there is no change when tape is applied cross the muscle fibers, and the excitability of motor neurons decrease all the more when tape is applied in direction of travel. However, $\mathrm{Fu}$ et al. [11] examined the effect of Kinesio taping on quadriceps strength of healthy athletes by isokinetic dynamometry. They concluded that no significant difference in muscle strength was found either immediately after tape application or after 12 hours of taping. In addition, Chang et al [1], Cools et al [12], Lee et 
al[13], Wong et al [14], and Lee et al [15] also reported that it does not cause any change in the excitability of muscles in normal adult.

It is known that tactile stimulation on skin by taping influences excitability of central nerve system while interacting with motor control in addition to sufficiently changing muscle power as well [4]. If this hypothesis is true, it may be inferred that KT would affect maximal power and muscle activity in normal adults.

Accordingly, this research was conducted to study how maximal power and muscle activity of erector spinae are affected after applying non-stretched tape on erector spinae that is extended to its maximum as mentioned by Kase et al [2].

\section{METHOD}

\section{Subjects of study}

As shown in $<$ Table 1>, subjects for this study were 30 healthy adult males in their 20s who have no abnormalities in their spinal column and no history in their lumbar regions. Signed study consent forms regarding voluntary participation in this study were received from test subjects and subjects were randomly allocated into experimental or control group with 15 subjects in each group.

\section{Measuring maximal power and muscle activity}

Patient was laid face down to measure maximal power and muscle activity of erector spinae. One hand of therapist fixed the pelvis while the other hand lifted the thoracic followed by verbal command of therapist saying "start" upon which test subject extended his trunk to its maximum and allowed for maximal resistance during which maximal voluntary isometric contraction (MVIC) was induced for 5 seconds. In this time, Digital Dynamometer(Power Track II, JTECH medical, USA) was used to measure maximal power of erector spinae regarding trunk maximal extension and surface EMG was used to record the MVIC value at the same time as well. This was followed by approximately 10 minute rest and then muscle activity of erector spinae was measured through active trunk extension. Once all pre-tests were completed, trunk was bent to its maximum after which non-stretched KT with width of $5 \mathrm{~cm}$ was applied from center of posterior superior iliac spine to T1 level following erector spinae on both sides. Afterwards, maximal power was re-measured in lying down position identical to the pre-test and then after 10 minute break, muscle activity of erector spinae was measured through the active trunk extension. Three trials were conducted for each subject and the mean value of the 3 trials was recorded for analysis.

Post intervention was conducted in control group without Kinesio taping of the erector spinae. After maximal voluntary isometric contractions for 5 seconds duration, only the 3seconds values of the RMS were used to compare with the mean value except for the first and last 1-second.

\section{EMG signal processing}

During the trunk extension, surface EMG (MP150 BIOPAC System Inc. CA. USA) was used to measure the root mean
square(RMS) of muscle activity in three muscles, which are iliocostalis lumborum, multifidus and longissimus. TSD 150B surface EMG electrode with inter-electrode distance of $20 \mathrm{~mm}$ was used. Active electrode of iliocostalis lumborum was attached $1 \mathrm{~cm}$ anterior to $\mathrm{L} 2$ level at line that connects back of iliac crest and inferior angle of rib while active electrode of multifidus was attached at the lateral side of spinous process of $5^{\text {th }}$ lumbar vertebra at $3 \mathrm{~cm}$ distance. For longissimus, it was attached at the right lateral side of spinous process of $1^{\text {st }}$ lumbar vertebra at $2 \mathrm{~cm}$ distance [http://seniam.org]. To prevent displacement of electrode during movement, it was securely fastened using bandage and reference electrode was attached at cervical.

Before attaching surface electrodes, skins of all subjects were sanitized with alcohol to reduce skin resistance. Settings were $1,000 \mathrm{~Hz}$ for sampling rate, $30 \mathrm{~Hz}$ for low band-pass filter, $500 \mathrm{~Hz}$ for high band-pass filter and $60 \mathrm{~Hz}$ for notch filter. Normalization was calculated by converting pre and post measurement data into percentage based on MVIC values.

\section{Data analysis}

In order to verify differences between pre and post measurement values for experimental and control groups by using SPSS 14.0K for Windows, paired t-test was conducted. To verify statistical significance between the two groups, independent t-test was conducted. Significant probability was $\mathrm{p}<0.05$.

\section{RESULTS}

\section{General characteristics of subjects}

Test was conducted for total of 30 participants in which both experimental group and control group had 15 male subjects each. Average age, height and weight for experimental group was 23 years old, $175 \mathrm{~cm}$ and $71.47 \mathrm{~kg}$, respectively, while for control group, it was 21 years old, $174.27 \mathrm{~cm}$ and $67.53 \mathrm{~kg}$, respectively. Results of homogeneity test between the two groups showed no difference ( $\mathrm{p}>0.05)$.

Table 1. General characteristics of subjects

\begin{tabular}{|c|c|c|c|}
\hline & Experimental & Control & $p$ \\
\hline & Mean \pm SD & Mean \pm SD & \\
\hline Gender(male) & 15 & 15 & \\
\hline Age $(\mathrm{yrs})$ & $23 \pm 3.76$ & $21.60 \pm 2.03$ & 0.215 \\
\hline Height $(\mathrm{cm})$ & $175 \pm 7.04$ & $174.27 \pm 3.94$ & 0.727 \\
\hline Weight $(\mathrm{kg})$ & $71.47 \pm 10.97$ & $67.53 \pm 8.59$ & 0.283 \\
\hline
\end{tabular}

2. Difference of muscle power and muscle activity in experimental and control groups

Pre and post intervention maximal power for erector spinae and muscle activities for iliocostalis lumborum, multifidus and longissimus in experimental and control groups are shown in $<$ Table $2>$. Results of verifying significance in these values showed no statistical significance between pre and post intervention in both groups $(\mathrm{p}>0.05)$. 
Table 2. Pre and post significant difference on the maximal power and muscle activity of erector spinae within group

(unit : \%)

\begin{tabular}{|c|c|c|c|c|}
\hline & & Pre & $\mathrm{Po}$ & \\
\hline & & Mean \pm SD & Mean \pm SD & \\
\hline \multirow[t]{4}{*}{ Exp.Group } & Max. power & $87.86 \pm 24.41$ & $93.40 \pm 20.51$ & 0.207 \\
\hline & Iliocostalis & $58.39 \pm 15.38$ & $49.72 \pm 17.98$ & 0.067 \\
\hline & Multifidus & $62.73 \pm 21.72$ & $51.70 \pm 19.31$ & 0.085 \\
\hline & Longissimus & $48.70 \pm 14.80$ & $39.42 \pm 16.48$ & 0.078 \\
\hline \multirow[t]{4}{*}{ Control } & Max. power & $79.90 \pm 20.93$ & $82.06 \pm 22.69$ & 0.558 \\
\hline & $\begin{array}{l}\text { Iliocostalis } \\
\text { Lumborum }\end{array}$ & $62.59 \pm 19.22$ & $52.45 \pm 17.46$ & 0.081 \\
\hline & Multifidus & $54.65 \pm 12.98$ & $54.32 \pm 15.93$ & 0.906 \\
\hline & Longissimus & $48.22 \pm 15.82$ & $4104+14.89$ & 0.069 \\
\hline
\end{tabular}

3. Significant difference between experimental and control groups

Results of significant difference between experimental and control groups showed no statistical significance between the groups as shown in $<$ Table $3>(\mathrm{p}>0.05)$.

Table 3. Significant difference between experimental and control groups

\begin{tabular}{|c|c|l|c|c|}
\hline \multicolumn{1}{|c}{} & Experimental & Control & \multirow{2}{*}{ (unit : \%) } & $\mathrm{p}$ \\
\hline & Mean \pm SD & Mean \pm SD & & \\
\hline Max. power & $5.53 \pm 16.19$ & $2.16 \pm 13.98$ & 0.609 & 0.547 \\
\hline $\begin{array}{l}\text { Iliocostalis } \\
\text { Lumborum }\end{array}$ & $8.66 \pm 16.93$ & $10.14 \pm 20.92$ & -0.212 & 0.834 \\
\hline Multifidus & $11.02 \pm 23.06$ & $0.33 \pm 10.77$ & 1.626 & 0.115 \\
\hline Longissimus & $9.27 \pm 18.85$ & $7.17 \pm 14.10$ & 0.346 & 0.732 \\
\hline
\end{tabular}

\section{CONCLUSIVE DISCUSSIION}

This research was conducted to study how KT affects maximal power and muscle activity when non-stretched KT is attached on the skin with erector spinae fully extended by having normal adults in their $20 \mathrm{~s}$ as test subjects. Its results showed no statistical significance in maximal power and muscle activity of erector spinae.

Accordingly, results of this study showed that KT has limitations in increasing muscle activity of erector spinae in normal adults.

Results of this study can also be known from previous studies in which Chang et al [1] applied KT on forearms of 21 healthy college athletes to understand the effects of KT on maximal grip power and power sense and reported that there was no change in maximal grip power and no statistical difference between control and placebo group was present. Fu et al [11] examined whether or not KT could alter peak torque and total work after the application of tape to the anterior knee and thigh in 14 healthy young athletes by using a isokinetic dynamometer and also showed that there were no statistical differences between no-taping, immediately after taping and 12 hours after taping. Lee et al [13] also reported that there was no statistical significance after applying KT to quadriceps femoris and measuring peak torque by using isokinetic machine and muscle activity in vastus medialis, vastus lateralis and rectus femoris. Lee et al [15] reported as well that there was no statistical significance before and after taping based on results of measuring nerve conduction velocity of radial nerve, ulnar nerve and median nerve after KT application on anterior of forearm. Janwantanakul and Gaogasigam [16] similarly presented that taping has no effect on muscle activity through results from EMG. In addition, Cools et al [12] also reported that there was no difference before and after taping based on results of measuring muscle activity by using EMG after applying tape to scapular of normal adult.

Accordingly, in summary of this study and previous study, it can be understood that KT applied on skin neither increases nor decreases the muscle activity and the muscle power.

As mentioned in the introduction, it is known that tactile stimulation on skin by KT interacts with motor control while influencing excitability of central nervous system and is enough to change muscle power [4]. However it can be understood that tactile stimulation by $\mathrm{KT}$ is not adequate to even change the muscle power.

Application of KT on skin has no effect on the maximal power and the muscle activity as presented in results of this study. The basis to support of present study is that $\alpha$-motor neuron innervate to extrafusal fiber and $\gamma$-motor neuron innervate to intrafusal fiber are simultaneously activated, which is called the $\alpha-\gamma$ co-activation theory [17]. In other words, although afferent input of sensory neuron that arises from applicable muscle reduces when extrafusal muscle fiber contracts, sensitivity of afferent nerve fibers in group Ia and II within the applicable muscle does not reduce but is sustained instead when intrafusal muscle fibers contract. As a result, excitability of motor neuron that causes efferent excitation is sustained instead of either decreasing or increasing. Accordingly, as shown in this study, it is likely that muscle power and muscle activity show no change due to continual input of afferent neuron of intrafusal muscle fibers when KT is applied on skin-if indeed skeletal muscle under the skin is actually shortened.

When KT is applied on the skin with muscle fully extended and tape not stretched, wrinkles appear on the taped skin once the joint returns to original position. As skin is lifted upwards due to the KT, circulation of blood, lymph fluids and tissue fluids increase in this space through which muscle function is recovered [2]. Based on such theoretical basis, the KT was applied on erector spinae hypothesizing that the KT would affect muscle contractibility as well, but present results showed no change to the muscle power and the muscle activity. However, Slupik et al[8] stated that KT increase the electromyographic activity of the vastus medialis muscle after 24 hours, and even maintenance of motor activity after 2 days of KT. Otherwise, the present study was measured immediate effect of KT, so following study need to conducted delay effect of KT.

As a result, it can be known through this study that the KT has no immediate effect on muscle power and muscle activities of normal adults. 


\section{ACKNOWLEDGEMENT}

This work was supported by Kyungnam University Foundation Grant, 2012.

\section{REFERENCE}

[1] H. Y. Chang, K. Y. Chou, and J. J. Lin et al, "Immediate effect of forearm Kinesio Taping on maximal grip strength and force sense in healthy collegiate athletes," Phys Ther Sport, vol. 11, no. 4, 2010, pp. 122-127.

[2] K. Kase, J. Wallis, and T. Kase, Clinical therapeutic applications of the Kinesio Taping method. Tokyo, Japan: Kinesio Taping Association, Ken Ikai Co. Ltd, 2003.

[3] T. Halseth, J. W. McChesney, and M. DeBeliso et al, "The effects of Kinesio taping on proprioception at the ankle," J Sports Sci Med, vol. 3, 2004, pp. 1-7.

[4] W. C. Chen, W. H. Hong, and T. F. Huang et al, "Effects of kinesio taping on the timing and ratio of vastus medialis obliquus and vastus lateralis muscle for person with patellofemoral pain, J Biomech, vol. 40(S2), 2007.

[5] F. Garcia-Muro, A. L. Rodriguez-Fernandez, and A. Herrero-de-Kucas, "Treatment of myofascial pain in the shoulder with Kinesio Taping, A case report," Manual Therapy, vol. 15, 2010, pp. 292-295.

[6] L. Kalichman, E. Vered, and L. Volchek, "Relieving symptoms of meralgia paresthetica using Kinesio Taping: A pilot study," Arch Phys Med Rehabil, vol. 91, 2010, pp. 1137-1139.

[7] J. H. Lee, W. G. Yoo, "Treatment of chronic Achilles tendon pain by Kinesio taping in an amateur badminton player," Physical Therapy in Sport, vol. 13, 2012, pp. 115-119.

[8] A. Slupik, M. Dwornik, and D. Bialoszewski, "Effect of Kinesio Taping on bioelectrical activity of vastus medialis muscle, Preliminary report," Ortopedia, Traumatologia, Rehabilitacja, vol. 9, 2007, pp. 644-651.

[9] D. Morrisey, "Proprioceptive shoulder taping," J Bodywork Movement Ther, vol. 4, no. 3, 2000, pp. 189194.

[10] C. M. Alexander, M. McMullan, and P. J. Harrison, "What is the effect of taping along or across a muscle on motorneurone excitability? A study using Triceps Surae," Man Ther, vol. 13, no. 1, 2008, pp. 57-62.

[11] T. C. Fu, A. M. Wong, and Y. C. Pei et al, "Effect of Kinesio taping on muscle strength in athletes-A pilot study,” J Sci Med Sport, vol. 1, no. 2, 2008, pp. 198-201.

[12] A. M. Cools, E. E. Witvrouw, and L. A. Danneels, "Does taping influence electromyographic muscle activity in the scapular rotators in healthy shoulder," Manual Therapy, vol. 7, no. 3, 2002, pp. 154-162.

[13] M. H. Lee, E. C. Kim, and H. S. Jeong et al, "The Effect of Kinesio taping on peak torque and muscle activity of quadriceps muscle in healthy subjects," Int J Contents, vol. 6 , no. 1, 2010, pp. 1-5.

[14] O. M. H. Wong, R. T. H. Cheung, and R. C. T. Li, "Isokinetic knee function in healthy subjects with and without Kinesio taping," Physical Therapy in Sport, 2012, pp. 1-4.

[15] M. H. Lee, C. R. Lee, and J. S. Park et al, "Influence of Kinesio Taping on the Motor Neuron Conduction Velocity," J Phys Ther Sci, vol. 23, 2011, pp. 313-315.

[16] P. Janwantanakul, and C. Gaogasigam, "Vastus lateralis and vastus medialis obliquus muscle activity during the application of inhibition and facilitation taping techniques," Clin Rehabil, vol. 19, 2005, pp. 12-19.

[17] L. Lundy-Ekman, Neurosicence: Fundamentals for rehabilitation, 3ed, 2007, pp. 198.

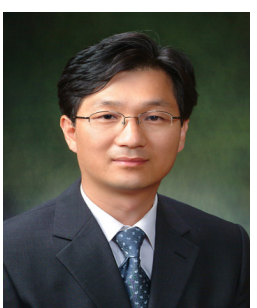

\section{Moon-Hwan Lee}

He received the degree of B.S., M.S., and $\mathrm{Ph}, \mathrm{D}$ in the department of physical therapy from Daegu university, Korea in 2000, 2002, and 2005 years respectively. His main research interests were exercise physiology and pain control mechanism.

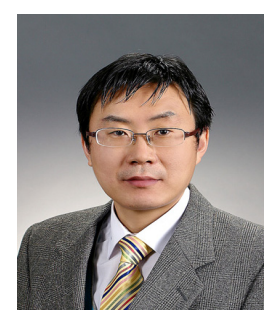

\section{Seong-Yeol Kim}

He received the degree of M.S. and Ph.D in the department of physiotherapy from Samyook university of Korea in 2004, 2009. His main research interests include musculoskeletal pain control using the Kinesiotaping and Clinical kinesiology. 